\title{
La Identidad Profesional como Problema: El Caso del "Psicólogo-Psicoanalista” en la Argentina (1959-1966)*
}

\author{
Professional Identity as a Problem: The Case of the "Psychologist-Psychoanalyst" in Argentina (1959-1966)
}

Alejandro Dagfal ${ }^{\mathrm{I}}$

\section{Resumen}

En Argentina, la creación de las carreras de Psicología, a fines de los años 1950, fue seguida por la invención de un nuevo rol profesional: el del "psicólogo de orientación psicoanalítica". Sin embargo, sus competencias en el campo de la clínica no estaban legalmente establecidas, y eran celosamente preservadas por los psiquiatras y psicoanalistas más conservadores. Al mismo tiempo, los creadores de las carreras con un perfil científico no tenían ninguna intención de que los psicólogos se dedicaran a las prácticas psicoterapéuticas. Así, la identidad profesional de esos primeros psicólogos-psicoanalistas se fue construyendo de manera reactiva, por oposición a las restricciones que suponía el rol auxiliar que les era propuesto, tanto desde el campo médico como desde las propias carreras. Por otra parte, los psiquiatras y psicoanalistas más progresistas funcionaron como modelo identificatorio "positivo" que les permitió forjarse una identidad profesional posible en el campo de la clínica. Este trabajo aborda este proceso desde un punto de vista histórico.

Palabras-clave: Historia de la psicología; identidad profesional; psicoanálisis; Argentina.

\section{Abstract}

In Argentina, the creation of psychology programs, at the end of the 1950s, was followed by the invention of a new professional role: that of the "psychologist with psychoanalytic orientation". Nevertheless, its competences in the clinical area were not legally recognized and they were kept with zeal by the most conservative psychiatrists and psychoanalysts. At the same time, the program founders, scientifically oriented, did not expect psychologists to get into psychotherapeutic practice. Thus, the professional identity of the first psychologists was gradually built in a reactive manner, opposing the restrictions implied by the auxiliary role that was proposed to them both in the medical field, and in the psychology programs themselves. On the other hand, the most progressive psychiatrists and psychoanalysts acted as a "positive" model of identification, which somewhat allowed for the construction of a professional identity in the clinical field. This paper deals with this process from a historical point of view.

Keywords: History of psychology; professional identity; psychoanalysis; Argentina.

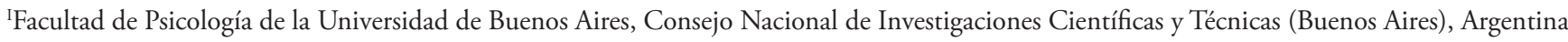

\section{El Psicólogo como Psicoanalista}

La implantación del psicoanálisis en la Argentina es un fenómeno cuya magnitud ha sido destacada por los historiadores de la disciplina ${ }^{1}$. Esto es aún más remarcable si se considera la realidad de otros países con fuerte tradición psicoanalítica, como Francia o Brasil, donde las ideas freudianas, a pesar de su popularidad, siempre han tenido que disputar un espacio con orientaciones psicológicas llamadas "científicas", que también tenían una presencia de larga data (Dagfal, 2011; Ohayon, 1999; Roudinesco, 1986).

En Argentina, luego dela reacción antipositivista de los años 1930, la tradición experimental de principios de siglo apenas si tuvo continuadores reconocidos. Aunque en los años 1950 algunos de los fundadores de las carreras de Psicología hayan querido reflotar esa tradición, su empresa se vio rápidamente condenada al fracaso, lo cual no

\footnotetext{
Considerando que, en principio, el psicoanálisis no es una disciplina exclusivamente universitaria ni implica una titulación otorgada por el estado, existen pocos estudios cuantitativos confiables sobre el psicoanálisis y los psicoanalistas, tanto en la Argentina como en el resto del mundo. En el plano local, la mayoría de esos trabajos se refieren a la enorme incidencia del freudismo en las carreras de Psicología (AUAPsi, 1998; Di Doménico \& Vilanova, 1990; Litvinoff \& Gomel, 1975; Vezzetti, 1998b). Por ejemplo, uno de los primeros estudios sociológicos realizados con psicólogos graduados de la UBA (entre 1961 y 1969) mostraba que se habían dedicado a la práctica clínica en más del $90 \%$ de los casos. Aunque esta elección no hubiera excluido actividades profesionales en otras áreas, la proporción resultaba abrumadora, y se correlacionaba con la adopción del psicoanálisis en sus distintas vertientes (Litvinoff \& Gomel, 1975). Por otra parte, desde un punto de vista cualitativo y comparativo, la importancia que reviste el psicoanálisis dentro del "campo psi" argentino es un dato internacionalmente aceptado, según veremos más adelante.
} 
hizo más que acentuar la hegemonía de la clínica en general y del modelo teórico psicoanalítico en particular. En ese sentido, si bien en los años 1940 los primeros psicoanalistas oficialmente reconocidos fueron médicos en su gran mayoría, a partir de los años 1960, con el egreso de los primeros psicólogos, se fue conformando una nueva figura profesional, la del "psicólogo-psicoanalista", en la medida en que, muy rápidamente, ellos adoptaron masivamente el psicoanálisis, no solo como marco teórico privilegiado, sino también como modelo de práctica y referencia identitaria. Y esto es particularmente llamativo, ya que esta adopción del psicoanálisis, según veremos, no solo se produjo sin ningún tipo de cobertura legal, sino que tuvo lugar de manera imprevista, contra los proyectos de casi todos los personajes involucrados en la organización del campo psi.

Con el paso del tiempo, cambiarían las modas teóricas y los autores de referencia. La fenomenología existencial cedería su lugar al estructuralismo y la escuela inglesa (Melanie Klein) a la francesa (Jacques Lacan). Sin embargo, el psicólogo argentino iba a seguir definiendo su identidad profesional en relación con el psicoanálisis, modelo que, en sus diversas variantes, ya ha guiado su práctica durante cerca de medio siglo.

En todo caso, la presencia del psicoanálisis como un elemento fundamental en la composición del panorama de las ideas psicológicas en la Argentina es un dato unánimemente reconocido, tanto por los cultores del freudismo como por sus adversarios más acérrimos $^{2}$. Ha sido objeto de numerosos trabajos, algunos de los cuales han sido muy exhaustivos y rigurosos (Balán, 1991; Plotkin, 2001; Vezzetti, 1989, 1996). Sin embargo, en lo que atañe específicamente al campo profesional de la psicología, los estudios que han tomado esta presencia privilegiada como un problema histórico a investigar son más escasos (Borinsky, 1998b, 1998c; Carpintero \& Vainer, 2004; Dagfal, 2009a; González \& Dagfal, 2012; Del Cueto \& Scholten, 2003; Klappenbach, 2000; Vezzetti, 2004; Visacovsky, 2002). En general, la tendencia establecida en el seno de las "profesiones psi" ha sido considerar

\footnotetext{
Un ejemplo de ello, a nivel internacional, es que el famoso Libro negro del psicoanálisis comienza afirmando que "Francia, junto con la Argentina, es el país más freudiano del mundo" (Meyer, 2005, p. 7). Al mismo tiempo, Élisabeth Roudinesco, refiriéndose al psicólogo argentino, ha escrito que se trata de "una rara avis, en la medida en que el psicoanálisis ha sido para él una referencia ineluctable durante cinco décadas (Roudinesco, 2009, p. 24).
}

esta hegemonía como un dato de la realidad, como un estado de cosas "normal", sin preguntarse mayormente por las causas y las consecuencias de este fenómeno singular. En ese sentido, nuestra intención es recuperar el asombro ante el lugar central que las ideas freudianas ocupan en el ámbito profesional de las disciplinas psicológicas en la Argentina, valiéndonos para ello de un análisis histórico-crítico que incorpora algunas nociones de la sociología de las profesiones. De este modo, trataremos de valorar en toda su dimensión este elemento característico de los discursos y las prácticas psicológicos producidos en ese país.

\section{La Cuestión de la Profesionalización y de la Identidad Profesional}

Es sabido que el concepto de identidad no pertenece al psicoanálisis, sino más bien a un conjunto de disciplinas, entre las cuales la Psicología y la Sociología tienen un rol preponderante. De por sí, la "identidad personal" resulta una noción problemática, sobre la que pueden encontrarse infinidad de teorizaciones diferentes e incluso contrapuestas ${ }^{3}$. Otro tanto ocurre con la idea de "identidad profesional" que, pese a ser un elemento central de la Sociología de las profesiones, nunca llegó a generar consensos extendidos en lo que respecta a su definición. Por ese motivo, en este escrito nos manejaremos con una noción un tanto sui generis de la identidad profesional que engloba los aportes de diferentes autores.

Es indudable que cuando se habla de identidad profesional se está haciendo alusión a una dimensión colectiva que implica la auto-representación de un grupo profesional, es decir, a la idea que determinados profesionales se hacen de sí mismos. Y esta no es estática; no se basa en una suerte de foto congelada, sino que deriva más bien de un relato dinámico, construido con mitos y olvidos, con exaltaciones de ciertas regiones del pasado y con zonas menos nítidas. Como toda operación de la memoria colectiva, esta

\footnotetext{
Sin hablar específicamente de identidad personal, a partir del concepto de identificación (que justamente subraya las dificultades de toda identidad) dentro del psicoanálisis puede pensarse muy someramente en las contribuciones de Sigmund Freud, con su teoría del narcisismo, en Jacques Lacan, con su estadio del espejo como fundante de la realidad psíquica, o en Kohut, con su idea de self, tan expandida en el mundo anglosajón. Respecto de la Sociología, no pueden ignorarse aportes como los de George Mead y su teoría de los roles.
} 
narración - que no puede dejar de compararse con una "novela familiar" — viene a responder ciertas preguntas, como "¿qué somos?", “¿a qué nos dedicamos?”, “¿cuáles son nuestras prerrogativas?”, "¿qué filiaciones reconocemos?", “¿quiénes son nuestros aliados?”, “¿cuáles son nuestros rivales?”, etc. La compleja trama estructurada con el conjunto de respuestas que se da a estos interrogantes implica cierto posicionamiento simbólico que orienta el accionar de cualquier grupo profesional. Poco importa si este relato es plenamente consciente, si opera de manera inconsciente o si combina elementos manifiestos con otros menos evidentes; lo cierto es que configura el sentido común con el que se manejan los miembros de un grupo profesional, tanto en sus relaciones entre pares como en lo tocante a otros grupos profesionales y al público en general. Según Abbott, se establece así una "jurisdicción cultural" que implica la apropiación y el control de una determinada zona de problemas (Abbott, 1988) .

Dicho de otro modo, la conformación de una identidad profesional también trae aparejada la delimitación de una esfera de competencias. Y si pensamos la profesión con la lógica bourdiana del "campo", se constata que no está exenta de luchas y relaciones defuerza, en la medidaen quequienes detentan posiciones dominantes, a partir de la acumulación de un capital simbólico que siempre es escaso - y que, por lo tanto, es fuente de disputa - , controlan el ingreso o el ascenso del resto de los miembros (Bourdieu, 1966, 1976). De este modo, se pone de relieve el carácter conflictivo de la legitimidad y lo reconocimiento en cualquier campo profesional, ya que sólo pueden provenir de pares que, a su vez, no dejan de competir por la obtención de legitimidad y reconocimiento, lo cual los sitúa en una posición de "juez y parte". Para Abbott, sin embargo, la dinámica de las profesiones que él entiende en términos de sistema - no viene tanto de la competencia entre pares sino de aquélla entre profesiones por la determinación de los límites de cada jurisdicción.

Las fronteras jurisdiccionales están continuamente en disputa, tanto en la práctica local como en el plano nacional.

Sobre este tema, ver también los textos ya clásicos de Elliott (1975) y Larson (1977). En cuanto al mundo francófono, pueden consultarse con provecho Dubar (1991) y Dubar y Tripier (1998). Para el contexto argentino, véanse Neiburg y Plotkin (2004) y Gómez Campo y Tenti Fanfani (1989).
Su historia es la verdadera determinación histórica de las profesiones. Los reclamos jurisdiccionales proveen el impulso y el modelo para los desarrollos organizacionales. Por lo tanto, una Sociología histórica de las profesiones, que pretenda ser efectiva, debe empezar por estudios de caso de las jurisdicciones y de las disputas jurisdiccionales (Abbott, 1988, p. 2).

En esta perspectiva, una profesión - es decir, "un grupo ocupacional exclusivo que aplica conocimiento abstracto a casos particulares" - se desarrolla cuando una jurisdicción queda vacante, sea porque acaba de ser creada o porque un antiguo ocupante la ha abandonado o ha perdido una parte considerable del control que ejercía sobre ella (Abbott, 1988, p. 8) ${ }^{5}$. Si bien esta visión es muy discutible, sirve para pensar cómo cada disciplina busca establecer un claro monopolio sobre determinada esfera de competencias, aunque, en la práctica, otras (profesionales y no profesionales) también aspiren al control de esa misma zona de problemas. Por ejemplo, si tomáramos el caso de la Psicología en EEUU, históricamente, según Abbott, el dominio en juego era el de los "problemas personales", que entre 1850 y 1950 fueron abordados sucesivamente por la religión y la Neurología, para luego ser disputados, ya en el siglo XX, por la Psiquiatría, las Psicoterapias, la Psicología Clínica y el Trabajo Social. En esa zona, el monopolio nunca parece haber sido muy claro ya que siempre coexistieron reclamos convergentes de distintas disciplinas. Aunque algunas tuvieran mayor control en determinados momentos, nunca llegaron a afirmar sus pretensiones de manera excluyente ${ }^{6}$.

\section{El Nacimiento de la Psicología: Una Disciplina y una Profesión Cuestionadas}

Más allá del carácter mítico que adquirió el famoso laboratorio de Psicología experimental fundado por Wilhelm Wundt en Leipzig, si se

Para este autor, la capacidad de abstracción posibilita la supervivencia de una profesión, en la medida en que le permite definir viejos problemas de maneras novedosas.

Para Abbott, en EEUU, a partir de los años 1920, el psicoanálisis fue un elemento importante tanto en la constitución del dominio de la Psiquiatría como en el de las psicoterapias. 
considera que las primeras carreras de Psicología y la primera asociación científico-profesional de psicólogos fueron creadas en EEUU a fines del siglo XIX, habría que afirmar, como lo hace Kurt Danziger, que "la Psicología como disciplina autónoma es una invención norteamericana" (Danziger, 1979, p. 25). A lo cual podría agregarse que el psicólogo, como un nuevo profesional, también es un invento norteamericano. Más aún si se piensa que, en ese país, a principios del siglo XX, los desarrollos de la Medicina y la Filosofía eran aún muy incipientes, y en todo caso menos importantes que los de la Psicología 7 .

Antes del siglo actual [se refiere al siglo XX en EEUU], las ideas psicológicas eran producidaseintercambiadas ampliamente entre filósofos, hombres de la medicina, economistas, políticos, historiadores, artistas y otros. Lo que en la historia más reciente resulta absolutamente novedoso es la aparición de grupos de especialistas que realizan demandas, crecientemente exitosas, de monopolio de la verdad psicológica. Los miembros de estos grupos se han instituido ellos mismos, $\mathrm{y}$ han sido gradualmente aceptados, como árbitros de lo que constituye o no un conocimiento psicológico válido [...]. Ciertas técnicas empíricas fueron aplicadas muy extensamente a problemas psicológicos en el siglo XIX por filósofos profesionales, naturalistas, médicos y aficionados. Pero los cambios cruciales no se dieron hasta que la aplicación de estas técnicas fue usada para legitimar la demanda del monopolio del conocimiento psicológico válido por parte de una comunidad de especialistas autoconsciente y organizada (Danziger, 1979, pp. 25-26).

Si bien, como hemos dicho, en EEUU el surgimiento de esa comunidad de especialistas fue muy temprano, no sucedió lo mismo en Latinoamérica, donde las primeras carreras universitarias de Psicología

De hecho, la célebre APA fue creada en 1892, 12 años antes que su homóloga alemana. Y la sociedad profesional de filosofía no fue más que un desprendimiento de la APA, producido en 1901. A diferencia de Alemania, la Psicología no era una rama de la Filosofía, sino que la Filosofía había tenido que diferenciarse del tronco de la Psicología. (conducentes a un título habilitante) fueron creadas medio siglo más tarde: en Guatemala en 1946, en Colombia en 1947, en Chile en 1948, en Brasil en 1953, en Perú y Argentina en 1955 (Klappenbach \& Pavesi, 1994). En cuanto a Europa, pueden mencionarse los casos de Francia (1947), Suiza (1965) y Rusia (1966) (Vilanova, 1993). Particularmente en Francia, la Psicología, como disciplina y profesión, fue muy criticada desde diferentes perspectivas filosóficas, que no dejaban de considerarla una mera provincia dentro de sus territorios (y ciertamente no la más respetable) ${ }^{8}$. Por ejemplo, en 1928, Georges Politzer comparaba los 50 ańos de historia de la Psicología con una "epopeya de desilusiones", en la que primaban promesas incumplidas e investigaciones aisladas, como si se tratara de "un estanque de ranas" (Politzer, 1928/1966). En definitiva, la Psicología era una "ciencia hecha de paciencia", que rechazando toda crítica estaba más cerca de su disolución que de cualquier forma de organización. Y su diagnóstico sobre ella era concluyente: no bastaba con podar algunas ramas de la Psicología; había que talar el árbol entero. En cuanto a la profesión, su visión no era más alentadora:

Lo característico en una ciencia es cierta sabiduría respecto de una materia determinada, y gracias a la cual se goza de cierto poder sobre las cosas pertenecientes a dicha materia [...]. Pero tomad un psicólogo: os hablará de las pretensiones de la Psicología; os contará la penosa historia de su ciencia; os dirá que se ha llegado a eliminar la noción de alma, la teoría de las facultades. Si le preguntáis en qué consiste su ocupación, os hablará de la vida interior [...]. Razón tenéis: el psicólogo no sabe nada y no puede nada. Es el pariente pobre en la inmensa familia de los servidores de la ciencia (Politzer, 1928, pp. 41-42).

Tres décadas más tarde, otro filósofo, Georges Canguilhem, iba a formular una crítica sin concesiones al proyecto de Daniel Lagache, uno de los artífices de la profesionalización de la Psicología en

Si nos detenemos particularmente en el contexto francés, esto se debe a la importancia que tuvo para "la invención" del psicólogo en la Argentina, según veremos más adelante. 
Francia. Lagache, que era médico y psicoanalista, en 1947 , en su clase inaugural como profesor de Psicología General en la Sorbona, había esbozado una "teoría general de la conducta" que trataba de hermanar los enfoques humanistas y naturalistas, las psicologías experimental y clínica, para sentar las bases de esa nueva profesión, en la que el psicoanálisis tendría un lugar de privilegio. Esta concepción, que pregonaba la unidad de la psicología, bajo la égida de la conducta, guió los pasos de los primeros psicólogos franceses del mismo modo en que una década más tarde iba a tener una enorme incidencia en la formación de los primeros psicólogos argentinos. En consecuencia, la célebre crítica que le formularía Canguilhem, en 1956, apuntaba en realidad a un proyecto que estaba en vías de expansión; de allí, quizás, su virulencia. Según Canguilhem - que en este punto retomaba los argumentos de Politzer - , la pregunta por el ser de la Psicología resultaba particularmente incómoda para los psicólogos, cosa que no sucedía a los filósofos con los interrogantes sobre la Filosofía.

Pero para la Psicología, la pregunta por su esencia o, más modestamente, por su concepto, cuestiona también la existencia misma del psicólogo, en la medida en que al no poder responder exactamente sobre lo que es, se le hace muy difícil poder responder por lo que hace. Sólo puede, entonces, buscar, en una eficacia siempre discutible, la justificación de su importancia como especialista, de la cual él no se lamentaría en absoluto, pero que en el filósofo generaría un complejo de inferioridad.

Al decir que la eficacia del psicólogo es discutible, no se quiere decir que sea ilusoria; simplemente se desea destacar que esta eficacia está sin duda mal fundada, en tanto no hay pruebas de que ella se deba a la aplicación correcta de una ciencia; es decir, en tanto que el estatuto de la Psicología no está determinado de tal manera que se la deba tener por algo más y mejor que un empirismo compuesto, literalmente codificado para los fines de la enseńanza. En efecto, de numerosos trabajos se tiene la impresión de que mezclan una filosofía sin rigor, una ética sin exigencia, y una medicina sin control (Canguilhem, 1958, p. 1) ${ }^{9}$.

En cuanto a la supuesta unidad de la que hablaba su amigo Lagache, Canguilhem no era menos incisivo, ya que la consideraba más "un pacto de coexistencia pacífica concertado entre profesionales" que una "esencia lógica". Sin embargo, por esa misma época, otro filósofo - discípulo de Canguilhem —, que por entonces era profesor de Psicología, elaboraba una visión menos negativa de la disciplina. Nos referimos al joven Michel Foucault, quien difería en parte con las concepciones de Politzer y de su propio maestro, aunque se situaba en una perspectiva análoga, tratando de resumir la historia de la Psicología entre 1850 y 1950 (Foucault, 1957). En ese siglo, para Foucault, la Psicología había abandonado gradualmente los postulados naturalistas que habían signado su nacimiento, para poder adaptarse a la especificidad de su objeto de estudio. Tratando de ser precisa y objetiva, se enfrentó a su propia paradoja, y debió reconocer que el ser humano no podía ser abordado con los principios y métodos de las ciencias de la naturaleza. Así, entre el siglo XIX y el siglo XX, el filósofo francés esbozaba una suerte de dirección evolutiva para la disciplina, que iba del "prejuicio de la naturaleza" hacia el "descubrimiento del sentido", alejándose del positivismo de sus orígenes. Este tránsito desde el orden natural hacia el plano de la significación se había realizado por diversas vías teóricas, entre las cuales el Psicoanálisis había sido la fundamental, al lado de la fenomenología (de Husserl a Jaspers) y del historicismo diltheyano. En el plano de la práctica, según Foucault, este pasaje había permitido a la Psicología una mejor aprehensión de su objeto, esto es, de lo anormal, de lo patológico, de los distintos niveles de contradicción del hombre consigo mismo. Se había apropiado así de nuevos dominios (educación, medicina mental, organización de los grupos) y se había interrogado sobre nuevos problemas (como el desempeño escolar, la inserción del enfermo en la sociedad, la adaptación del hombre a su trabajo, etc.). En todo caso, se había ofrecido como "fundamento científico-racional" para toda una serie de prácticas. No obstante, como ciencia y como profesión, la Psicología aún tenía muchas deudas, que Foucault se encargaba de convertir en programa:

Ver también Roudinesco (1993) y Braunstein (1999). 
De modo que la Psicología se obligó a sí misma en el curso de su historia a una renovación total y al descubrir un nuevo status del hombre se impuso a sí misma, como ciencia, un estilo nuevo. Debió buscarse nuevos principios y develar para sí misma un nuevo proyecto: doble tarea que los psicólogos no siempre han comprendido con rigor, y que intentaron muy a menudo completar con muy poco. Unos, aún comprendiendo la exigencia de proyectos nuevos, permanecieron atados a los antiguos principios del método: de eso dan cuenta los psicólogos que intentaron analizar la conducta, pero que utilizaron para hacerlo los métodos de las ciencias de la naturaleza. Otros no comprendieron que la renovación de los métodos implicaba la actualización de nuevos temas de análisis: de allí las psicologías descriptivas que permanecieron ligadas a viejos conceptos. La renovación radical de la Psicología como ciencia del hombre no es, por lo tanto, sólo un hecho histórico cuyo desarrollo pueda situarse en los últimos 100 años; es aún una tarea incompleta que queda por cumplir $y$, en ese sentido, permanece a la orden del día (Foucault, 1957, pp. 1-2).

En todo caso, estos debates sobre la Psicología (como disciplina de conocimiento y como profesión, como ciencia natural o como ciencia humana, como reino unificado o dominio fragmentado), que hemos seguido a través de algunos textos de filósofos franceses, iban a estar muy presentes en la Argentina de los años 1950 y 1960, período en el que se produciría el nacimiento del psicólogo como un nuevo profesional.

\section{La "Invención" del Psicólogo en la Argentina}

Para comprender los avatares de la construcción de la identidad profesional del psicólogo argentino, es necesario recapitular, aunque más no sea brevemente, el proceso de profesionalización en ese país ${ }^{10}$. Podría afirmarse que los esbozos de ese proceso tuvieron lugar

10 Este tema ya lo hemos tratado in extenso en otro trabajo (Dagfal, 2009a) y de manera muy resumida en otro más reciente (Dagfal, 2012). a fines de los años 1940 y a principios de los años 1950, durante lo que se ha dado en llamar "el primer peronismo". En efecto, en el transcurso de los dos primeros gobiernos de Juan Domingo Perón (19461952 y 1952-1955), con el apoyo del Estado, se desarrolló vertiginosamente una psicología aplicada particularmente bajo la forma de la psicotecnia y la orientación profesional -, que resultaba particularmente apta para complementar los proyectos industrialistas del gobierno. La orientación profesional, por ejemplo (que servía para vincular el mundo de la educación al del trabajo utilizando toda una suerte de técnicas psicológicas), alcanzó rango constitucional. Ello implicó el nacimiento de numerosas instituciones destinadas a fomentarla y aplicarla, así como la creación de carreras menores destinadas a formar profesionales capaces de realizar esa tarea. Fue a partir de la iniciativa de algunas de esas instituciones que, en 1954, se organizó en la provincia de Tucumán el Primer Congreso Argentino de Psicología. Como los psicólogos aún no existían en tanto tales, los participantes eran en su mayoría profesores de psicología, filósofos de orientaciones diversas, sacerdotes, psicotécnicos, médicos psiquiatras e, incluso, algunos psicoanalistas (Dagfal, 1997). Lo cierto es que, en una sesión plenaria de ese evento, se aprobó una declaración tendiente a "la creación de la carrera universitaria del psicólogo profesional" a escala nacional:

El Primer Congreso Argentino de Psicología declara la necesidad de crear la carrera universitaria del psicólogo profesional con arreglo a las siguientes condiciones: I. Se establecerá como sección autónoma en las Facultades de carácter humanístico, aprovechando los institutos ya existentes y la enseñanza que se imparte en esas y en otras Facultades que puedan ofrecer su colaboración (Medicina, Derecho, Ciencias Económicas, etc.); II. La carrera comprenderá un plan completo de asignaturas teóricas y la debida intensificación práctica en las distintas especialidades de la profesión psicológica, otorgando los títulos de Licenciado en Psicología (previa tesis de Licenciatura) y de Doctor en Psicología (previa tesis de Doctorado); III. Establecerá además carreras menores de Psicólogos auxiliares 
en los distintos dominios de la terapia médica, pedagogía, asistencia social, organización industrial, y otros campos de aplicación a las necesidades de orden nacional y a las regionales servidas por las diferentes universidades argentinas (Anónimo, 1954, pp. 121-122).

Al margen del certamen se efectuaron diversas reuniones animadas por el propósito de organizar la licenciatura y doctorado en Psicología, volviendo a actualizar diversos antecedentes en ese sentido que no habían cristalizado por complejos factores. Así se trazó un programa de estudios para la carrera de psicólogo, cuyo comienzo debía surgir en las facultades de filosofía y letras de Buenos Aires y La Plata y desarrollarse en un ciclo de cinco años (Horas, 1961, p. 345).

Parece indudable que, en el ocaso del primer peronismo, quienes se dedicaban a la Psicología en la Argentina ya habían arribado a algunos consensos indispensables para la profesionalización de la disciplina. No obstante, en los meses subsiguientes, la mayoría de los proyectos presentados en las distintas universidades no llegaron a buen puerto, con lo cual cabe preguntarse sobre las diferencias entre el desarrollo de la Psicología en el ámbito académico y en el profesional ${ }^{11}$.

Todo indica que, en ese período, si bien el ámbito profesional reclamaba una mayor legitimación del quehacer psicológico, el académico respondía a otro tipo de imperativos (lo cual resulta entendible si se piensa que las universidades más importantes habían sido una suerte de bastión de la resistencia antiperonista) (Mangone \& Warley, 1984). Luego del derrocamiento de Perón, en septiembre de 1955, la dictadura que tomó el poder en cierto modo delegó el manejo de las universidades a los sectores intelectuales más liberales (progresistas y no progresistas), que durante el gobierno depuesto habían tenido que prosperar en las sombras. Las universidades nacionales comenzaron entonces una etapa de normalización institucional (no exenta

11 La única excepción fue la Universidad Nacional del Litoral, por lo que la primera carrera de Psicología argentina se creó en la ciudad de Rosario, el 6 de abril de 1955, aunque la duración de su estructura original sería efímera. de proscripciones) y de modernización curricular que permitió el pleno desarrollo de las ciencias humanas y sociales. En ese marco universitario reformista, signado por un cierto humanismo laico, la Psicología se perfilaba como un saber indispensable.

En este nuevo período (autodenominado "Revolución Libertadora") se generaron las condiciones académicas para la profesionalización de la disciplina, que vinieron a sumarse a las condiciones del ámbito profesional que ya parecían estar presentes desde la etapa anterior. Quizás de este modo sea más fácilmente entendible que, después de que las universidades recuperaran su autonomía, en sólo dos ańos - entre 1957 y 1959 - , la carrera de Psicología haya sido creada en cinco universidades nacionales: en Buenos Aires, en 1957; en La Plata, Córdoba y San Luis, en 1958 y en Tucumán, en 1959 (además de la de Rosario, que había sido reabierta en 1956). De este modo, al contar con un lugar específico de legitimación académica y de formación para los psicólogos, comenzaba en Argentina la historia de la Psicología como disciplina profesional. Sin embargo, el tipo que comenzó a desarrollarse en esas casas de estudios tenía muy poco que ver con aquélla que había proliferado durante la era peronista. Aunque no se tratara en absoluto de una disciplina homogénea, ya que en cada carrera convivían múltiples proyectos, es claro que la psicotecnia y la orientación profesional no tendrían el mismo lugar de antańo.

Resumir qué pasó en cada una de las carreras recién creadas excedería los límites de este trabajo. Sin embargo, en este respecto, pueden señalarse algunas cuestiones. Por un lado, al no haber psicólogos titulados, el cuerpo profesoral de las carreras se fue conformando de manera no sistemática, con los recursos humanos disponibles en cada ciudad o en ciudades vecinas, lo cual resultó en un caleidoscopio de teorías, orientaciones y formaciones (Dagfal, 2009a; Monasterio, 2011). De hecho, los mismos fundadores reconocían filiaciones muy diversas, que mezclaban a médicos españoles con psiquiatras argentinos, a filósofos con pedagogos, y hasta había lugar para más de un autodidacta sin título universitario ${ }^{12}$. En todo caso, según veremos, los proyectos disciplinares

\footnotetext{
2 Entre los fundadores, la única excepción era Nuria Cortada (19212013), quien ya contaba con un título de psicólogo obtenido en el extranjero. En 1949, luego de estudiar filosofía en Mendoza, había obtenido un "Master of Arts in Clinical Psychology" en la Ohio State University, bajo la tutela de Victor Raimy. En 1952, además, había pasado nueves meses en París, trabajando en el hospital Sainte-Anne, donde fue dirigida por Pierre Pichot.
} 
y profesionales que guiaron a la mayoría de los fundadores tenían muy poco que ver con lo que sucedería después. Muchos definían la Psicología en términos científicos bastante tradicionales, ligados a problemas biológicos, filosóficos y antropológicos. En cuanto al rol profesional, había pocos acuerdos. La mayoría pensaba que la clínica no debía ser una orientación privilegiada en la formación de grado, ya que su ejercicio estaba legalmente reservado a los médicos $^{13}$. Entre fines de 1958 y 1960, hicieron una tentativa de organizar en común el campo de la Psicología académica, para lo cual se reunieron en Buenos Aires en varias oportunidades. Frente al problema de la falta de profesores formados en las áreas que ellos querían privilegiar, en 1959 dejaban constancia de su impotencia por escrito:

Existen varias especialidades psicológicas para cuya investigación y enseñanza el país carece de expertos idóneos. Por su generalidad y su trascendencia, ello constituye un problema universitario y nacional. En esa situación se encuentran, con carácter de primera necesidad, las asignaturas siguientes: Psicología de Laboratorio, Psicología Industrial, Orientación Profesional [...]. Para Psicología de Laboratorio y Psicología Industrial, cabría orientar las consultas en particular hacia Italia, Bélgica y Francia (Departamento de Orientación Vocacional de la UBA, 1959, pp. 1-2).

La descripción del "estado de situación” más que reflejar la realidad de la disciplina, dejaba ver cuáles eran los ideales de los fundadores. Era obvio que, para esa época, en la Argentina, a diferencia de otros países, la "Psicología de laboratorio" prácticamente había desaparecido, al igual que otras formas de aquélla considerada científica u objetiva. Por otra parte, en la era post-peronista, la psicología

\footnotetext{
Jaime Bernstein, un pedagogo adleriano especializado en tests y pruebas proyectivas, fue una de las excepciones a esta regla. Desde un comienzo, promovió una psicología clínica que implicaba el ejercicio de las psicoterapias por parte de los psicólogos. Junto con Enrique Butelman (un estudiante de filosofía que nunca llegó a recibirse), en 1945 había fundado la editorial Paidós, especialmente dedicada a la Psicología y a las ciencias humanas. Ambos terminarían siendo algunos de los profesores más influyentes en las carreras de Buenos Aires y Rosario.
}

industrial y la orientación profesional tampoco estaban ya entre las ramas más populares. Y si no había profesionales formados en esas áreas era más bien porque habían quedado identificados con el gobierno depuesto en 1955. En todo caso, es claro que estos profesores rápidamente debieron asumir los límites de sus propias ambiciones, por lo que tuvieron que reformular sus proyectos. En ausencia de docentes capacitados para todas las áreas, acordaron que, después de una licenciatura común, cada carrera se especializara en la orientación más adaptada a su propia tradición, a las demandas del ambiente, y a los docentes de los que disponía. Siguiendo esa lógica, en los estudios de posgrado, la carrera de Buenos Aires debía especializarse en clínica y en psicología social, la de Córdoba en psicología industrial, la de Rosario en psicometría, la de San Luis en psicopedagogía y la de La Plata en psicología experimental ${ }^{14}$.

Este consenso venía anunciándose desde 1959, pero recién se plasmó en 1960 , al cabo de una serie de reuniones en el Consejo Nacional de Ciencia y Tecnología (CONICET), que había sido fundado en 1958. Sin embargo, la tarea iba a ser dificultosa, ya que las gestiones iniciadas en Europa para contratar un profesor de psicotecnia no tuvieron ningún éxito. Ni Dino Mazzei, de Florencia, ni José Germain o José Pinillos, de Madrid, ni Franziska Baumgarten, de Berna, aceptaron las invitaciones que se les cursaron para instalarse en Argentina (Monasterio, 1961). Si los diversos proyectos de los fundadores parecían acercarse a la idea de una formación científica para los futuros psicólogos, podría decirse que los alumnos tendrían otro tipo de expectativas. Lo cual no iba a dejar de incidir en el curso de los acontecimientos.

Para muchos de los fundadores, la Psicología se situaba de plano dentro de lo que Foucault denominaba "el prejuicio de la naturaleza" o de lo que Lagache, más conciliador, llamaba "enfoque naturalista”. Tan es así que, en un momento dado, surgió la discusión sobre la pertinencia de crear las carreras de Psicología en facultades de medicina (y no en las de filosofía y letras o humanidades, como 
finalmente sucedió) (Anónimo, 1954; Monasterio, 2011). Para otros profesores, particularmente los más jóvenes (y los que fueron llegando a las carreras con el transcurso de los años), ella debía ubicarse en el plano de la significación. Servía para interpretar, entre otras cosas, los cambios sociales e individuales, los procesos políticos, las transformaciones de la familia y el nuevo lugar asignado a la mujer. Lo cierto es que esta bipartición entre la Psicología concebida como ciencia natural o como disciplina del sentido, por sus consecuencias para el rol profesional, iba a ser una de las grandes divisorias de aguas en los primeros debates generados en el seno de las carreras, e incluso más allá de ellas.

A diferencia de Francia, donde el psicoanalista Daniel Lagache había desempeñado un rol muy importante en la creación de la carrera (Ohayon, 1999), los principales responsables de la profesionalización universitaria de la Psicología argentina no tenían ninguna intención de privilegiar el desarrollo de una psicología clínica de filiación psicoanalítica. Algunos de ellos, como Gino Germani, se interesaban en el psicoanálisis, pero no en el plano de la clínica, sino en vistas a una renovación más general de las ciencias sociales. Algunos filósofos, como Luis Juan Guerrero y Luis María Ravagnan, terminaron ocupándose del psicoanálisis, pero como teóricos que no tenían ningún proyecto profesional. Marcos Victoria, un neurólogo y literato, se había interesado en el psicoanálisis como disciplina médica, por lo que, al igual que Ángel Garma, se opondría tenazmente al ejercicio psicoterapéutico de los psicólogos. Si la médica española Fernanda Monasterio había incluido una rama clínica en la carrera de grado de La Plata, había definido las competencias del psicólogo, en ese dominio, de la siguiente manera: "el diagnóstico psicológico (con o sin pruebas técnicas), la ejecución de tests proyectivos, el consejo psicohigiénico, y el tratamiento verbal de los conflictos de la personalidad (funcionales y reversibles) en cuanto colaborador del médico, como el radiólogo o el bioquímico" (Facultad de Humanidades y Ciencias de la Educación, 1958, p. 24). Es decir que se trataba de un rol bastante limitado, que no se inspiraba en el psicoanálisis y quedaba subordinado a la tutela del médico en lo tocante a las psicoterapias. Considerando tales posiciones de algunos de los fundadores de las carreras, no resulta extraño que, en los primeros planes de estudio, el psicoanálisis apenas ocupara un lugar muy discreto. Bajo rótulos diversos, en principio, no se le asignaban más de una o dos materias (Psicología Profunda, Psicología de la Personalidad, Psicoanálisis, etc.). Sin embargo, veremos que, contra la voluntad más o menos explícita de los fundadores, los primeros graduados de las carreras de Psicología, en su gran mayoría, se orientaron hacia la práctica clínica liberal, haciendo a menudo un análisis personal a lo largo de sus estudios.

\section{El Ingreso del Psicoanálisis a las Carreras y el Rol de los Estudiantes}

Si los fundadores de las carreras tenían un proyecto más bien científico para la disciplina (estuviera o no ligado a las prácticas de laboratorio), que no se centraba en la clínica y menos aún en el psicoanálisis, ¿qué sucedió en la Argentina que, muy rápidamente, el psicoanálisis adquirió un lugar de tanto privilegio en la formación universitaria? Nuestra hipótesis es que, por toda una serie de factores convergentes, ese giro ocurrió poco tiempo después de la creación de las carreras, aproximadamente entre 1959 y 1962, durante el transcurso de los estudios de los primeros ingresantes. Por un lado, hay que pensar que la Asociación Psicoanalítica Argentina (APA) - la única institución en el país reconocida por la International Psychoanalytical Association (IPA) había sido creada varios años antes, en 1942 (Balán, 1991). Si bien había comenzado a desarrollarse tímidamente, casi como una sociedad secreta, a partir de 1955, en un marco de vertiginosa renovación social y cultural, en su seno se había desarrollado toda una "tendencia exogámica" que, a tono con los aires de la época, buscaba aplicar el psicoanálisis más allá del encuadre tradicional, proyectándose a nuevos espacios de práctica (como los hospitales públicos) y abriéndose a cruces teóricos originales (con la teoría de los grupos, la fenomenología existencial, el pensamiento sistémico, etc.).

Aunque el representante más ilustre de esta corriente "exogámica", Enrique Pichon-Rivière, nunca haya sido docente en las carreras de psicología, sus enseñanzas llegaron a los claustros por una doble vía. En primer lugar, con el transcurso de los años, ese psiquiatra de origen francés se transformó en una figura cuasi mítica, de modo que sus teorías y experiencias innovadoras pasaron a formar parte del patrimonio colectivo de toda una generación de psiquiatras, psicólogos y psicoanalistas (por no decir de dos). En segundo lugar, sus discípulos más destacados 
(José Bleger, Fernando Ulloa, David Liberman, Edgardo Rolla etc.) sí llegaron a ser profesores en las carreras de Buenos Aires, Rosario y La Plata, donde tuvieron una recepción más que favorable de parte de los estudiantes. Básicamente, Pichon-Rivière abogaba por un nuevo paradigma psicosocial, que en el plano teórico combinaba de manera heterogénea una concepción del inconsciente extraída de la llamada escuela inglesa (Melanie Klein pero también Wilfred Bion) y la articulaba con una definición de la conducta tomada de la psicología francesa (de Janet a Lagache pasando por el primer Politzer). Al mismo tiempo, no olvidaba la experiencia vivida de la fenomenología existencial (de Sartre a Merleau-Ponty), la psicología social elaborada en EEUU (Kurt Lewin, George Mead, etc.), ni dejaba de dotarse de un cierto barniz humanista, propio de los escritos del joven Marx (Fabris, 2007; Vezzetti, 1998a). El resultado era una mezcla ecléctica, que a nivel profesional se traducía en la definición del psicólogo como agente de cambio, lo cual estaba muy en sintonía con las demandas de compromiso social que venían del estudiantado. De allí que los discípulos de Pichon-Rivière, a pesar de su juventud, hayan sido tan bien recibidos en las nuevas carreras (Dagfal, 2000).

Por otra parte, no puede ignorarse que, a nivel internacional, el psicoanálisis fue un ingrediente fundamental del fenómeno que ha dado en llamarse "los años 60". En efecto, en la Argentina, más allá de la asociación oficial y del ámbito académico, el psicoanálisis ya tenía una implantación en la cultura que, desde los años 1930, venía dándose por diversas vías y que a fines de los 1950 iba a acelerarse y multiplicarse de manera exponencial (Plotkin, 2001; Vezzetti, 1998a). La expansión de las clases medias iba a ser acompañada por una gran difusión de las ideas freudianas, que pasaron a formar parte de los nuevos consumos culturales, como el cine de Hollywood o la Coca-Cola. Al mismo tiempo, la renovación de la psiquiatría que había traído aparejada la segunda posguerra incluía el psicoanálisis como uno de los discursos fundantes del campo de la salud mental. De este modo, las prácticas inspiradas en la obra del maestro vienés hacían su ingreso en el dispositivo de salud pública, llegando incluso a los sectores menos pudientes (Dagfal, 2009b; Visacovsky, 2002). Y todo ese proceso, a su vez, era amplificado por editoriales como Paidós, que, sin dejar de tener una vinculación directa con la universidad, ponían a los nuevos autores (incluyendo a los autores locales) al alcance de un público cada vez más amplio ${ }^{15}$.

Por último, para entender el auge del psicoanálisis en las carreras de Psicología, el rol desempeñado por los primeros alumnos no puede ser soslayado. Menos aún si se considera que, en esa época, la universidad pública había vuelto a regirse por los principios reformistas, los cuales implicaban el gobierno tripartito de docentes, graduados y estudiantes. En cierto modo, ante una oferta curricular muy heterogénea, ellos funcionaron como un filtro, reteniendo los profesores que más los atraían y contribuyendo a expulsar a aquéllos que no contaban con su simpatía, además de tejer alianzas para la designación de autoridades afines.

Respecto del perfil del alumnado, la primera cuestión destacable era la amplia primacía del género femenino, ya que entre 80 y $90 \%$ de los ingresantes eran mujeres. En cuanto a la edad, podría decirse que había dos tipos de estudiantes. Por un lado, las que tenían 17 o 18 años, que luego de terminar la escuela secundaria se interesaban en la Psicología por curiosidad o por aspiraciones profesionales diversas. Por otra parte, estaban las más experimentadas, que habiendo realizado - o al menos iniciado - otra carrera, de pronto habían decidido que la Psicología respondía mejor a sus expectativas. Dentro de las facultades, ambos grupos se encontraban con un ambiente altamente politizado, marcado por el debate intelectual y por la necesidad de pronunciarse frente a temas de actualidad. Como nos informó Rosalía Schneider, en un mensaje electrónico fechado el 8 de abril de 2008, según todos los actores de la época,

\footnotetext{
El caso de esta editorial es particularmente curioso, ya que sus dos fundadores, Enrique Butelman y Jaime Bernstein, terminarían siendo profesores - e incluso directores - de las carreras de Psicología de Buenos Aires y Rosario. Al combinar la labor editorial con la tarea de gestión universitaria, podían darse el lujo de elegir y convocar profesores afines a su propia concepción de las ciencias del hombre, cuyos libros ya habían publicado o esperaban publicar muy pronto. Ese fue, por ejemplo, el caso de José Bleger, cuyo libro Psicoanálisis y dialéctica materialista salió por Paidós en 1958, un año antes de que su autor comenzara a dar clases en Rosario y Buenos Aires (Bleger, 1958). Particularmente en Buenos Aires, la llegada de Butelman y Bernstein supuso todo un viraje respecto del proyecto de los fundadores, viraje que contó con el apoyo de los estudiantes. En Rosario, en cambio, Bernstein fue directamente convocado para la reapertura de la carrera, en 1956, y rápidamente convocó a su amigo y socio, Butelman (Gentile, 2003; Klappenbach, 2001; Vezzetti, 2008).
} 
el clima de participación y la vocación de cambio eran denominadores comunes.

Entre los estudiantes de Psicología, de la UBA, habían lazos muy fuertes, de todo tipo (políticos, amorosos, etc.), con estudiantes y graduados de otras carreras de la Facultad, e incluso de la Universidad. Había algo que nos unía. Eran carreras nuevas (Psicología, Sociología, Antropología, Ciencias de la Educación) y todos estábamos aunados en abrir campos, en crear nuevas profesiones, en trabajar interdisciplinariamente, en ser críticos en la teoría y en la práctica, en incorporar el marxismo, en el compromiso político, en hacer la Revolución y en cambiar la sociedad.

Desde el comienzo nos dimos cuenta de que nuestra condición de alumnos implicaba varias cosas a la vez. Debíamos estudiar, pero, junto a eso - y ocupando un lugar más importante aun —, debíamos crear la carrera que teníamos que cursar [...]. El psicoanálisis picaba nuestra curiosidad. Nos dábamos cuenta, a medida que conocíamos algo más de nuestra ciencia, los comprometidos que estábamos como individuos con nuestra historia personal en aquello que se estaba construyendo. Muchos comenzamos a analizarnos, y con ello irrumpió otro gran momento de la carrera (Langleib, 1985, pp. 12-14).

Composición heterogénea del alumnado (de la carrera de Psicología de la UNLP). Gran expectativa. Entusiasmos. Apasionamientos. Gran politización del estudiantado. Asambleas y debate permanentes. Paros. Movilizaciones. Pasión. Lucha y decepción [...]. No caben dudas de que la propuesta del psicoanálisis fue, ya por entonces, la más rica, sistematizada, y coherente. La que nos aportó un conocimiento o una interrogación nueva sobre el ser humano.
Pero, a diferencia de lo que puede pasar hoy, era una no alienada, que incluía otros atravesamientos. Teoría de los grupos y de la comunicación, aportes de la filosofía existencial y hasta el estudio del funcionamiento neuro-endócrino y los efectos de los psicofármacos. Todo fue útil (Delucca, 1994, p. 2).

En este contexto, las "estudiantes primerizas", que tímidamente comenzaban a dar sus primeros pasos en el campo de la Psicología, muy rápidamente se convertían en jóvenes intelectuales y profesionales en germen. Entre los ritos iniciáticos de esas "mujeres modernas", además del primer cigarrillo o el primer pantalón, se agregaba también la primera sesión de análisis. Grupal, para las menos pudientes, o individual, para las más acomodadas, esa práctica empezaba a ser un ingrediente de la vida cotidiana. Del mismo modo, sus representaciones sobre la profesión fueron cambiando radicalmente. Aunque algunas hubieran comenzado la carrera pensando en modelos profesionales tradicionales, a medida que se iban modificando sus intereses intelectuales y existenciales, esos ideales difusos, en la mayoría de los casos, daban lugar a una vocación cada vez más definida. En realidad, se trataba de una elección que se conjugaba con la modificación del lugar de la mujer en la sociedad. En efecto, las estudiantes avanzadas ya no querían limitarse al dominio educativo o a la aplicación de tests, que implicaban roles más o menos clásicos, sino que preferían aventurarse también por territorios inexplorados. En el dominio de la clínica, por ejemplo, ellas consideraban poder asumir tareas más arriesgadas y de mayor reputación, como aquéllas ligadas a la cura, que generalmente se atribuían en exclusividad a los médicos. Si en un principio algunas de ellas (sobre todo las que no provenían de las grandes ciudades) se habían conformado con un rol menos prestigioso, comparable con el de las enfermeras, con el paso del tiempo, aspirarían a un reconocimiento semejante al de los médicos.

Cuanto más se formaban con profesores psiquiatras y psicoanalistas (que iban ingresando en todas las carreras en las materias más dispares), menos se resignaban estas jóvenes a no poder ejercer el mismo tipo de prácticas que ellos realizaban. Sobre todo considerando que ya habían establecido "relaciones transferenciales" con sus analistas (médicos en su gran mayoría), participaban en grupos de estudio 
privados con miembros de la APA y realizaban sus prácticas en instituciones clínicas, como el Servicio de Psicopatología del Hospital Lanús (Dagfal, 2009b). De este modo, comenzaban a entender qué era atender a un paciente, supervisar un caso y trabajar en equipo. Una vez que esta máquina fue puesta en marcha, parecía muy difícil detenerla con discursos normativos sobre la verdadera función del psicólogo, sobre su falta de competencias en el campo clínico o sobre los obstáculos legales que le impedían el ejercicio de las psicoterapias. El mercado para el psicoanálisis parecía haberse ampliado de manera inexorable, bastante más allá del control de la asociación analítica. Aunque los miembros de la asociación oficial también se hubieran beneficiado con esta expansión, recibiendo numerosos pacientes y nuevas demandas de supervisión y formación, la APA, en su conjunto, como institución, iba a ser muy reticente a aceptar a los psicólogos como miembros hasta entrados los años 1980.

Según una alumna de la segunda promoción de la UBA, que terminó sus estudios junto con los miembros de la primera, Adela Leibovich de Duarte, en una entrevista inédita concedida a Martín Cremonte y Eduardo Sincofsky en 1995, "la carrera de Psicología mucho tuvo que ver con el crecimiento geométrico de la APA. Se generó una especie de mercado cautivo, ya que no se podía acceder formalmente a esa institución. La formación era paralela, lo cual era un elemento muy difícil de digerir". Este punto de vista es compartido por otra alumna de la primera promoción de la UNLP:

Edgardo Rolla, titular de Psicología Profunda, también nos estimuló en el estudio del psicoanálisis y nos invitó a que nos incorporáramos a la APA. Antes de terminar la carrera, habíamos empezado a viajar a Buenos Aires a hacer seminarios. No a incluirnos en la institución, porque todavía no estábamos recibidos. Por esa época hicimos seminarios con PichonRivière, Bleger, Liberman, Ulloa, Pavlovsky [...]. Cuando nos recibimos, invitados por Rolla, fuimos a hacer el intento [...]. En ese momento, fuimos a tener una entrevista para ingresar a la APA, con el que estaba de presidente [...]. Nos hizo una entrevista a media docena de psicólogos que habíamos ido y nos dijo que no, que a los psicólogos no se los admitía. Que para ser psicoanalistas había que ser médicos [...]. Bueno, fue una equivocación de Rolla, y una desinformación nuestra. Claro, desde la formación que nosotros habíamos obtenido, él consideró que estábamos en condiciones de entrar. Realmente era un deseo de él que entráramos en la asociación; éramos sus primeros discípulos. Hicimos seminarios sueltos, pero no pudimos hacer la formación sistemática, porque estaba esa ley (la ley 12.912, reglamentada en 1954 por la ordenanza No 2.282), que decía que para hacer psicoterapia o para ser psicoanalista tenías que ser médico. Esa fue la segunda gran desilusión. La primera fue la del artículo 28 (que autorizaba a las universidades privadas a otorgar títulos habilitantes) y la segunda fue la del rechazo de la asociación. Que en realidad nos enfrentaba al hecho de que se nos había formado como psicólogos clínicos para hacer psicoterapia, y la ley decía que sólo la podían hacer los médicos (Delucca, 2003, pp. 86-87).

De este modo, en el seno de las carreras, esos estudiantes que habían funcionado como filtros para dejar pasar un cierto psicoanálisis y excluir otras tendencias teóricas, rápidamente tuvieron que confrontarse con las consecuencias concretas del hecho de no ser médicos. En todo caso, eso reafirmaba sus lazos con un psicoanálisis por fuera de las normas, descentrado respecto del circuito oficial. En ese sentido, las enseñanzas de Bleger y Rolla, por ejemplo, no obtenían su legitimidad de ninguna pertenencia institucional, sino de sus propios contenidos y proyecciones profesionales. Ante la mayoría de los estudiantes, ellos tenían más crédito por su relación con Pichon-Rivière y por haber intervenido en experiencias innovadoras, que por ser miembros de la APA.

En resumen, podría decirse que, luego de la creación de las carreras de Psicología, en la consideración de los estudiantes, los proyectos científicos y profesionales (bastante difusos) del grupo fundador fueron rápidamente desplazados 
por una concepción psicosocial que, si bien no era homogénea, por lo menos era novedosa. En ese proyecto alternativo, el psicólogo ya no aparecía como un científico riguroso, sino como un intelectual comprometido con el cambio social. Al mismo tiempo, el psicoanálisis se transformaba en la matriz teórica privilegiada toda vez que podía articularse en diferentes planos con todo tipo de experiencias y de concepciones innovadoras.

\section{Los Debates Profesionales como Catalizadores de una Identidad Reactiva}

Como era de esperar, los debates más acalorados sobre el rol del psicólogo no se dieron en el momento de la creación de las carreras, sino cuando los primeros estudiantes empezaban a obtener su título habilitante. Más específicamente, los médicos psiquiatras se percataron entonces de que la aparición de esta nueva figura profesional implicaba un riesgo inminente para el mantenimiento del monopolio médico en el dominio de las psicoterapias. En efecto, los médicos en general y los psiquiatras en particular habían sido los únicos profesionales legalmente habilitados para tratar las enfermedades "del espíritu". Pero la aparición de psicólogos que aspiraban a competencias clínicas amenazaba con alterar ese statu quo. De tal suerte, no es extrańo que la mayor parte de las disputas haya girado en torno del tema de "la cura por la palabra". En mayo de 1959, en la Universidad Nacional de La Plata (UNLP), un profesor del consejo directivo de la Facultad de Ciencias Médicas solicitó formalmente "la supresión de la rama clínica del ciclo superior de la carrera de Psicología”, ya que la práctica de la Psicología clínica implicaba para él una forma de "ejercicio ilegal de la Medicina” (UNLP, 1960, p. 43). Este acto marcaba el "inicio de las hostilidades" en el campo académico de la Psicología argentina. En el campo profesional, en el mes de octubre, el Colegio de Médicos de la provincia de Buenos Aires hizo publicar una solicitada en varios diarios locales, expresando su preocupación por la "práctica de la hipnosis" y por el "ejercicio ilegal de la Medicina" que las carreras de Psicología supuestamente favorecían. En realidad, se trataba de la presentación en sociedad de los mismos argumentos que iban a utilizarse, durante ese mismo mes, en la "Tercera Conferencia de Asistencia Psiquiátrica”, que se realizaría en Cuyo entre el 8 y el 10 de octubre de 1959.
Esta conferencia iba a representar el punto más álgido de estos conflictos profesionales. Sus temas principales fueron "la formación del personal psiquiátrico auxiliar" y los "títulos habilitantes para el estudio y el tratamiento del enfermo psíquico". Allí tuvieron cabida diferentes exposiciones, que mostraban las diferentes perspectivas desde las cuales los psiquiatras analizaban el problema. Para Gregorio Bermann, por ejemplo, un notorio psiquiatra de izquierda (que en 1956 había presidido el Primer Congreso Argentino de Psiquiatría), los psicólogos, simples "técnicos" de la Psicología aplicada, no estaban en condiciones de ocuparse de la psicología llamada médica. Él se asombraba entonces de que, en la carrera de Psicología de Córdoba, creada en 1958, hubiera una cátedra de psicoterapia cuyo titular no era médico.

Hecho inusitado, tanto más cuanto que esta enseńanza falta por entero en la Facultad de Medicina de la misma Universidad [...]. En este semestre se están dictando cursos de psicoanálisis, dedicados principalmente a alumnos de este Departamento. Es notoria pues la tendencia invasora de la Psicología, apuntando hacia la psicoterapia. Y he sido testigo de la desilusión de algunos estudiantes de Psicología cuando se les hacía notar que no estaban facultados para ejercer la psicoterapia (Bermann, 1960, p. 176).

La perspectiva de Bermann, sin embargo, era mucho más moderada que la de los representantes de la psiquiatría tradicional, quienes fueron los encargados de exponer la "posición oficial". Paradójicamente, a partir de 1958, con la asunción de un gobierno democrático, este sector había adquirido cierto poder dentro de las instituciones de salud mental, que hasta entonces habían estado en manos de psiquiatras reformistas ${ }^{16}$. De este modo, no es raro que la defensa

\footnotetext{
16 En 1958, Arturo Frondizi asumió como Presidente de la Nación, lo cual marcó el fin del régimen militar iniciado en 1955. No obstante, su poder fue muy restringido, teniendo que gobernar bajo tutela militar hasta el golpe de Estado de 1962. Contra todas las expectativas creadas, el gobierno de Frondizi fue, en muchos aspectos, tan o más conservador que el de los militares que lo habían precedido, particularmente en los dominios de la educación y la salud.
} 
de las prerrogativas médicas haya sido presentada por Omar Ipar, el director del Hospital Neuropsiquiátrico de Buenos Aires; Carlos Sisto, el secretario de la Comisión Nacional Consultiva en Salud Mental, y Juan Dichiara, el responsable de la especialización en Psiquiatría que dependía del Instituto Nacional de Salud Mental, creado en 1957 (Borinsky, 1998a). En una presentación mordaz, intitulada "Encrucijada actual de la Psiquiatría", se alarmaban "frente a la invasión de actores extraños a la Medicina, dispuestos a desvirtuar toda su historia, su técnica y sus penosas conquistas terapéuticas" (Ipar, Sisto \& Dichiara, 1959, citado por Carpintero \& Vainer, 2000). Ese discurso alarmista tenía una lógica simple, tendiente a despertar la conciencia corporativa y a reclutar nuevos adeptos:

¿Qué títulos pueden exigirse para tratar a un enfermo? [...]. Hasta ayer la pregunta era superflua y la respuesta obvia. Hoy, quizás más de un colega se sorprendería ante quien le planteara este interrogante. Ocupado en su quehacer cotidiano y ajeno a toda preocupación jurídica ignora una cantidad de irregularidades que por su misma repetición han creado un orden de cosas que a muchos parece natural y consagrado. Incluso desconozca que mañana egresarán de nuestras Facultades de Filosofía más de un millar de psicólogos que tendrán igual derecho que el suyo para el estudio y tratamiento de las enfermedades mentales (Ipar, Sisto \& Dichiara, 1959, citado por Borinsky, 1998a, p. 66).

En realidad, lo que estaba en discusión no era solamente "quién está preparado para curar", sino también, como trasfondo, "cómo se curan las enfermedades mentales", sabiendo que las opciones disponibles no eran complementarias sino excluyentes. Si los profesionales que no eran médicos sólo se apoyaban en la palabra como instrumento de curación, de ello se deducía que, necesariamente, tenían una concepción de la enfermedad que contradecía la de la medicina orgánica. En último análisis, eso era lo que se discutía cuando se planteaba el problema de los títulos necesarios para el ejercicio de las psicoterapias. Si se admitía que estas últimas no eran apenas un complemento de las terapias bioquímicas y orgánicas, y que obedecían a una lógica distinta de la de las ciencias naturales, ello implicaba el derrumbe de todo el edificio teórico de la psiquiatría contemporánea o la aceptación de que ésta no pertenecía al orden de la medicina llamada científica. Ambas posibilidades resultaban inadmisibles, por lo cual, para los psiquiatras, era crucial reafirmar el carácter subsidiario del trabajo psicoterapéutico de los no médicos. No obstante, no iban a estar solos en esta empresa, en la medida en que los profesores de Psicología que consideraban que esa disciplina era una ciencia natural (en su mayoría médicos) iban a sostener posiciones similares. Ese era el caso de Marcos Victoria, el primer director de la carrera de psicología de la UBA.

Hay un punto inatacable en la resistencia de los médicos a permitir la entrada de estos intrusos: es la existencia de la responsabilidad médica. El psicólogo no está vinculado por ningún juramento hipocrático al ejercicio de su profesión [...]. Una resolución inconsulta de la Universidad de La Plata, destinada a facilitar el ejercicio de la profesión a los futuros psicólogos que egresen de sus aulas, los autoriza a "ejercer la psicoterapia por medios verbales”. ¿Habrán pensado las autoridades de esa casa de estudios que un psicólogo inexperto ( $\mathrm{y}$ a quien no obliga ningún juramento médico) puede provocar el suicidio de un deprimido ansioso por una conducta terapéutica mal conducida? ¿Habrán pensado lo que puede ocurrir en el seno de una familia, uno de cuyos miembros presenta trastornos de conducta, con la entrada de una psicóloga improvisada (eso ocurre todos los días entre nosotros), sin la debida experiencia para afrontar situaciones psicosociales complejas y que ponen a prueba a los médicos más fogueados? [...]. Pero la falta de responsabilidad de los psicólogos de pacotilla no se detiene allí [...] (Victoria, 1965, pp. 21-23).

Esta toma de partido de quien fuera uno de los fundadores de la carrera de Psicología de la UBA no hacía más que ilustrar las razones por las cuales había sido excluido de ella. No obstante, cabe recordar que, 
con matices, sus ideas eran compartidas por muchos de los otros fundadores, que también se oponían al ejercicio autónomo de las psicoterapias por parte de los psicólogos. En ese contexto, es más fácil de entender a qué nos referimos cuando hablamos de la adopción de una identidad "reactiva" por parte de estos nuevos profesionales, que se sentían triplemente rechazados. En primer lugar, sus propios profesores les negaban competencia en un área en la cual ellos juzgaban que tenían mejor formación que la mayoría de los médicos (de hecho, en la carrera de Medicina apenas si había un par de materias que hicieran alusión a lo psíquico y a la cura de las enfermedades mentales). En segundo lugar, los psicoanalistas les negaban el acceso a la asociación oficial, aunque fueran "analistas oficiales" quienes los habían analizado y formado en las ideas freudianas. En tercer lugar, los psiquiatras querían relegarlos a un rol subalterno, amenazándolos incluso en el plano legal. Nuestra hipótesis es que, en gran medida, la identidad de los psicólogos se fue conformando como reacción ante estos roles menores (auxiliar de la psiquiatría, testista, psicotécnico, consejero) que les eran impuestos por figuras de mucho peso. Cuanto más se les negaba el reconocimiento de sus competencias en el campo de la clínica, más se aferraban al ejercicio de las psicoterapias desde una perspectiva psicoanalítica. En cierto modo, de manera dialéctica, la conciencia de un "nosotros" se fue constituyendo por oposición a la alteridad radical de "los otros" (Figura 1).

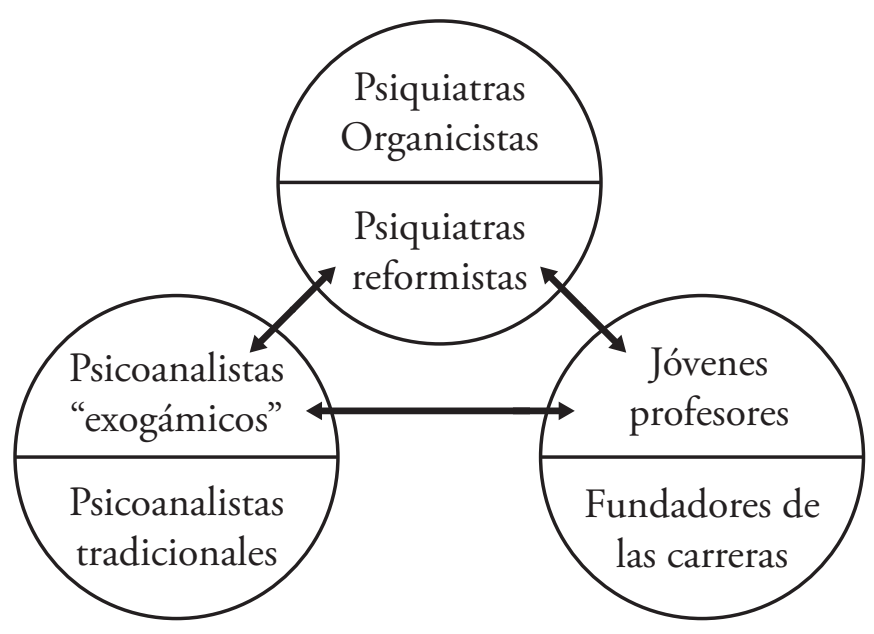

Figura 1. Alianzas y rivalidades en la conformación de una identidad profesional. Psicología como ciencia natural o disciplina del sentido

\section{Comentarios Finales}

Para concluir, sería justo reconocer que no todo fue reactivo en la construcción identitaria del psicólogo argentino. Hubo algunas figuras del "campo psi" que les sirvieron como referentes, esto es, como soportes para una identidad "proactiva". El más importante, muy probablemente, haya sido José Bleger. Siguiendo a Pichon-Rivière, como ya mencionamos, este psiquiatra-psicoanalista, miembro del Partido Comunista, combinaba el atractivo de las ideas freudianas con los imperativos de cambio social. Por un lado, enseñaba los fundamentos de una Psicología de la conducta que hermanaba la respetabilidad académica de Daniel Lagache con el militantismo de Georges Politzer. Por el otro, llevaba a los estudiantes a las villas miseria [favelas], para mostrarles los rudimentos de una Psicología preventiva que por entonces denominaba "psicohigiene".

Aunque no impulsara el rol clínico de los psicólogos, llegado el momento, pese a ser médico, los acompanó en su disputa con los psiquiatras. De hecho, pensaba que el psicólogo era el profesional mejor preparado para la actividad psicoterapéutica. Pero al mismo tiempo creía que "la carrera de Psicología tendría que ser considerada un fracaso desde el punto de vista social si los psicólogos quedan exclusivamente y en su gran proporción limitados a la terapéutica individual" (Bleger, 1962, p. 355, citado por Borinsly, 1998a, p. 68). Habría que ver en qué medida el golpe de estado del 1966 no fue el causante de que los psicólogos terminaran desoyendo esta segunda parte del credo blegeriano. En un momento en que la actividad pública se tornaba riesgosa, ellos fueron refugiándose cada vez más en los consultorios, siguiendo el modelo médico de atención privada, lo cual los mantenía al margen de las regulaciones estatales.

Otro referente de esos primeros psicólogos (de Rosario y Buenos Aires), fue Jaime Bernstein. En realidad, encarnaba una de las raras líneas de continuidad entre la Psicología aplicada desarrollada durante el peronismo y la nueva Psicología clínica de "filiación psicoanalítica". Bernstein había pasado de una orientación profesional ligada al trabajo y a la educación a una concepción clínica más integral, donde las técnicas proyectivas y su interpretación analítica ocupaban un lugar privilegiado. En esta dirección, todo indica que Bernstein tenía la determinación de contribuir a la constitución de este nuevo campo. Según el testimonio de una de las primeras ayudantes 
que trabajaron con él en Buenos Aires a partir de 1958, Ercilia "Nenuka" Rosenberg, en una entrevista inédita concedida a este autor, el 23 de noviembre de 2004 se trataba de algo así como una causa militante:

En la primera reunión de cátedra, Bernstein nos dijo que no olvidáramos este momento que estábamos viviendo, ya que no sólo se trataba del comienzo de nuestra carrera como docentes, sino también del comienzo de un proceso irreversible, en el cual las carreras de Psicología de todo el país iban a ser dirigidas por sus propios graduados [...]. Esta dimensión de proyecto, de causa, tenía un nombre, que no era psicoanálisis. Era la psicología clínica.

Sea como fuere, ya sea que se hablara de psicología clínica, psicohigiene o psicoanálisis, tanto Bleger como Bernstein, entre otros jóvenes profesores, parecían dispuestos a seguir el programa esbozado por Foucault en 1957, que implicaba una "renovación radical de la Psicología como ciencia del hombre". En esa empresa, en una jurisdicción profesional disputada, contarían con la ayuda de psiquiatras reformistas y de psicoanalistas "exogámicos". Todos ellos, a su vez, suscitarían la adhesión masiva de los estudiantes, quienes rechazaban los roles profesionales prescriptos por los fundadores más cientificistas, los psiquiatras organicistas y los psicoanalistas considerados "ortodoxos". De este modo, hace medio siglo, nacía en la Argentina la figura del psicólogo-psicoanalista, cuya existencia marca el panorama de la disciplina hasta la actualidad.

\section{Referencias}

Abbott, A. (1988). The System of Professions: an essay on the division of expert labor. Chicago: University of Chicago Press.

Anónimo (1954). Primer Congreso Argentino de Psicología. Humanidades, 34, 121-122.

AUAPsi. (1998). Programa de formación de especialistas en innovación curricular en psicología. Informe diagnóstico de la situación actual. Buenos Aires: Mimeo.

Balán, J. (1991). Cuéntame tu vida: una biografía colectiva del psicoanálisis argentino. Buenos Aires: Planeta.

Bermann, G. (1960). Nuestra psiquiatría. Buenos Aires: Paidós.

Bleger, J. (1958). Psicoanálisis y dialéctica materialista. Buenos Aires: Paidós.
Bleger, J. (1962). El psicólogo clínico y la higiene mental. Acta Psiquiátrica y Psicológica Argentina, 8 (4), 349-357.

Borinsky, M. (1998a). La disputa por la psicoterapia: la encrucijada de la psicología entre la crisis de la psiquiatría y el psicoanálisis. In Informe parcial de beca de iniciación. (pp. 65-82). Buenos Aires: CONICET.

Borinsky, M. (1998b). Un corte sincrónico en el estudio de la conformación de un campo profesional: el $2^{\circ}$ Congreso Argentino de Psicología. In Informe parcial de beca de iniciación. (pp. 83-97). Buenos Aires: CONICET.

Borinsky, M. (1998c). Cuatro polémicas en la constitución de la psicología como profesión. In Informe parcial de beca de iniciación. (pp. 98-110). Buenos Aires: CONICET.

Bourdieu, P. (1966). Champ intellectuel et projet créateur. Temps modernes, 246, 865-906.

Bourdieu, P. (1976). Le champ scientifique. Actes de la recherche en sciences sociales, (2/3), 88-104.

Braunstein, J. F. (1999). La critique canguilhemienne de la psychologie. Bulletin de Psychologie, 52 (2), 181-190.

Canguilhem, G. (1958). ¿Qué es la psicología? (M. T. Poyrazian, Trad.). Acceso el 31 de julio de 2013, en www.elseminario.com.ar (Reimpreso de Qu'est-ce que la psychologie?, en Revue de Metáphysique et de Morale, 1958, 1, y en Cahiers pour l'Analyse, marzo de 1966, 2).

Carpintero, E., \& Vainer, A. (2000). La historia de la desaparecida Federación Argentina de Psiquiatras (FAP). Trabajo presentado en el XVI Congreso Argentino de Psiquiatría, organizado por APSA en Mar del Plata.

Carpintero, E., \& Vainer, A. (2004). Las huellas de la memoria. Buenos Aires: Topía.

Dagfal, A. (1997). Discursos, instituciones y prácticas presentes en la etapa previa a la profesionalización de la disciplina psicológica en la argentina (19451955). Cuadernos Argentinos de Historia de la Psicología, 3 (1/2), 173-195.

Dagfal, A. (2000). José Bleger y los inicios de una "psicología psicoanalítica" en la Argentina de los años '60. Revista Universitaria de Psicoanálisis, Facultad de Psicología de la UBA, 139-170.

Dagfal, A. (2009a). Entre Parísy Buenos Aires. La invención del psicólogo (1942-1966). Buenos Aires: Paidós.

Dagfal, A. (2009b). O ingresso da psicanálise no sistema de saúde pública na Argentina. Psicologia em Estudo, 14 (3), 433-438.

Dagfal, A. (2011). Psychanalyse et psychologie. ParisLondres-Buenos Aires. París: Campagne Première. 
Dagfal, A. (2012). Historias de la psicología en la Argentina (1890-1966). Entre ciencia natural y disciplina del sentido. Ciencia Hoy, 126, 25-29.

Danziger, K. (1979). The social origins of modern psychology. In A. R. Buss (Ed.), Psychology in Social Context (pp. 25-44). New York: Irvington Publishers.

Del Cueto, J., \& Scholten, H. (2003). Notas para una investigación sobre ideología y psicología en Argentina (1965-1972). Buenos Aires: Tekné.

Delucca, N. (1994). Palabras de una veterana de la primera promoción de psicólogos a los estudiantes y futuros colegas. Boletín de la Comisión de Estudiantes de psicología, UNLP.

Delucca, N. (2003). Reportaje a Norma Delucca (Autores varios). Acheronta, 17. Acceso el 31 de julio de 2013, en www.acheronta.org/deluca17.htm

Departamento de Orientación Vocacional de la UBA (1959). Memorándum de la Primera reunión de carreras de psicología, 8 de marzo, 1-2.

Dubar, C. (1991). La socialisation. Construction des identités sociales et professionnelles. Armand Colin: París.

Dubar, C., \& Tripier, P. (1998). Sociologie des profesions. Armand Colin: París.

Elliott, P. (1975). Sociología de las profesiones. Tecnos: Madrid.

Fabris, F. (2007). Enrique Pichon-Rivière, un viajero de mil mundos. Génesis e irrupción de un pensamiento nuevo. Buenos Aires: Editorial Polemos.

Facultad de Humanidades y Ciencias de la Educación (1958). Actas del Consejo Académico, tomo 12. La Plata: UNLP.

Foucault, M. (1957). La Psicología de 1850 a 1950 (H. Scholten, Trad.). Acceso el 31 de julio de 2013, en www.elseminario.com.ar (Reimpreso de La psychologie de 1850 à 1950, en Histoire de la philosophie européenne (t. II), de D. Huisman y A. Weber, 1957, Paris: Librairie Fischbacher, y en Dits et écrits (t. I) (pp.120-137), de M. Foucault, 1994, Paris: Gallimard).

Gentile, A. (2003). Ensayos históricos sobre psicoanálisis y psicología. Rosario: Fundación Ross.

Gómez Campo, V., \& Tenti Fanfani, E. (1989). Universidad y Profesiones. Crisis y alternativas. Buenos Aires: Miño y Dávila.

González, E., \& Dagfal, A. (2012). El psicólogo como psicoanalista: Problemas de formación y autorización. Entrela universidady lasinstituciones. Intersecciones Psi. Revista Electrónica de la Facultad de Psicología de la UBA, 2 (5), 12-18. Acceso el 31 de julio de 2013, en http://intersecciones. psi.uba. ar/revista_ed_n_5.pdf\#page $=12$
Horas, P. (1961). La enseñanza de la psicología en la universidad argentina y otros comentarios. Anales del Instituto de Investigaciones Psicopedagógicas de la Universidad Nacional de Cuyo, 6, 339-354.

Ipar, O., Sisto, C., \& Dichiara, J. (1959). Encrucijada actual de la psiquiatria. In Tercera Conferencia Argentina de Asistencia Psiquiátrica. Buenos Aires: Ediciones I.T.E.M.

Klappenbach, H. (2000). El psicoanálisis en los debates sobre el rol del psicólogo. Argentina, 1960-1975. Revista Universitaria de Psicoanálisis, 2, 191-227.

Klappenbach, H. (2001). Dos editoriales en los comienzos de la profesionalización de la psicología en Argentina. Memorandum, 1, 61-71.

Klappenbach, H., \& Pavesi, P. (1994). Una historia de la psicología en Latinoamérica. Revista Latinoamericana de Psicología, 26 (3), 468-469.

Langleib, M. (1985). Crónica de la creación de la carrera de psicología. Revista Argentina de Psicología, 34, 12-14.

Larson, M. S. (1977). The rise of professionalism. A sociological analysis. Berkeley: University of California Press.

Litvinoff, N., \& Gomel, S. (1975). El psicólogo y su profesión. Buenos Aires: Nueva Visión.

Mangone, C., \& Warley, J. (1984). Universidad y Peronismo (1946-1955). Buenos Aires: Centro Editor de América Latina, Biblioteca Política Argentina.

Meyer, C. (Ed.) (2005). Le livre noir de la psychanalyse. Vivre, penser et aller mieux sans Freud. París: Les Arènes.

Monasterio, F. (1961). Memoria del Departamento de Psicología. La Plata: Facultad de Humanidades y Ciencias de la Educación, UNLP.

Monasterio, F. (2011). Entrevista a la Dra. Fernanda Monasterio Cobelo (por A. Dagfal). Revista de Historia de la Psicología, 32 (4), 37-64.

Neiburg, F., \& Plotkin, M. (Eds.) (2004). Intelectuales y Expertos La constitución del conocimiento social en la Argentina. Buenos Aires: Paidós.

Ohayon, A. (1999). Limpossible rencontre. Psychologie et psychanalyse en France 1919-1969. París: La Découverte.

Plotkin, M. (2001). Freud in the Pampas. The emergence and development of a psychoanalytic culture in Argentine. Stanford: Stanford University Press.

Politzer, G. (1928/1966). Crítica de los fundamentos de la psicología: el psicoanálisis. Buenos Aires: J. Álvarez.

Roudinesco, É. (1986). La bataille de cent ans. Histoire de la Psychanalyse en France (1925-1985). París: Seuil.

Roudinesco, É. (1993). Situation d'un texte: «Qu'estce que la psychologie? ». In E. Balibar, M. Cardot, F. Duroux, M. Fichant, D. Lecourt \& J. Roubaud 
(Eds.), Georges Canguilhem, philosophe historien des sciences (pp. 135-144). París: Albin Michel.

Roudinesco, É. (2009). Prólogo. In Dagfal, A. Entre París y Buenos Aires. La invención del psicólogo (1942-1966). Buenos Aires. Paidós.

Universidad Nacional de La Plata. (1960). Actas del Honorable Consejo Superior. La Plata: UNLP.

Vezzetti, H. (Ed.) (1989). Freud en Buenos Aires. Buenos Aires: Puntosur.

Vezzetti, H. (1996). Aventuras de Freud en el pais de los argentinos. Buenos Aires: Paidós.

Vezzetti, H. (1998a). Enrique Pichon-Rivière y Gino Germani: el psicoanálisis y las ciencias sociales. Anuario de Investigaciones, 6, 476-486.

Vezzetti, H. (1998b). Informe sobre el campo de la psicología: la situación de los posgrados. Buenos Aires: CONEAU.

Vezzetti, H. (2004). Los comienzos de la psicología como disciplina universitaria y profesional: debates, herencias, proyecciones sobre la sociedad. In M. Plotkin \& F. Neiburg (Eds.), Intelectuales y expertos. La constitución del conocimiento social en la Argentina (pp. 293-326). Buenos Aires: Paidós.

Vezzetti, H. (2008). Enrique Butelman: la enseñanza y los libros. In A. Leibovich de Duarte (Ed.),
Ayer y hoy. 50 años de enseñanza de la Psicología (pp. 155-166). Buenos Aires: Eudeba.

Victoria, M. (1965). El psicólogo contra el médico. In M. Victoria, Psicología para todos (pp. 21-23). Buenos Aires: Losada.

Vilanova, A. (1993). La formación de psicólogos en Iberoamérica. Acta Psiquiátrica y Psicológica de América Latina, 39 (3), 196.

Visacovsky, S. (2002). El Lanús. Memoria y politica en la construcción de una tradición psiquiátrica y psicoanalitica argentina. Buenos Aires: Alianza.

\section{Dirección institucional:}

Alejandro Dagfal

Avenida Independencia, 3065

Ciudad de Buenos Aires (C1225AAM)

E-mail: adagfal@club-internet.fr

Recibido el 31/07/2013

Revisado el 04/01/2014

Aceptado el 06/01/2014

* Este trabajo ha sido financiado por el CONICET y ha sido realizado en el marco del proyecto UBACyT: "El dispositivo 'psi' en el siglo $\mathrm{XX}$ : las disciplinas y la cultura intelectual”. 